\title{
Branding e experiência digital: redesign interativo para o website da Lola Cosmetics
}

\section{Branding and Digital Experience: interactive redesign for the Lola Cosmetics website}

Mayara dos Santos de Almeida ${ }^{[1]}$, Helena De Araujo Neves ${ }^{[2]}$ (orientadora)

\begin{abstract}
Resumo: Este artigo trata-se de um recorte de uma pesquisa que propôs um redesign interativo para o website da marca Lola Cosmetics. Neste artigo, contudo, são expostos aspectos relacionados a tal marca bem como ações que proporcionaram uma experiência digital para seus consumidores. A investigação possuiu um cunho qualitativo contemplando revisões bibliográficas sobre Experiência do usuário e Marketing contemporâneo - além de uma coleta de dados documental sobre a Lola Cosmetics - resultando na prática projetual exposta neste texto. Como resultado, apresenta-se a prática que teve por base os planos da experiência do usuário, presente na metodologia de projetual de Garret (2011), e que é demonstrada a partir de um fluxo do website da marca evidenciando tais ações através de um vídeo interativo.
\end{abstract}

Palavras-chave: Branding. Experiência. Design Digital. Design de interação. Lola Cosmetics. 
Abstract: This article is an outline of a survey that proposes an interactive redesign for the Lola Cosmetics website. In this article, however, aspects related to this brand are exposed as well as actions that have provided a digital experience for their consumers. The investigation has a qualitative character contemplating bibliographical revisions on User Experience and Contemporary Marketing - in addition to a collection of documentary data on Lola Cosmetics - resulting in the design practice exposed in this article. As a result, the practice based on user experience plans, present in Garrett's methodology project (2011), is presented and demonstrated from a flow of the brand website showing such actions through an interactive video.

Keywords: Branding. Experience. Digital Design. Interaction design. Lola Cosmetics.

\section{INTRODUÇÃO}

Este artigo tem como intuito evidenciar os resultados obtidos na prática projetual resultante de um Trabalho de Conclusão de Curso desenvolvido junto ao curso de Design Digital da Universidade Federal de Pelotas. Tal investigação buscou, através de uma revisão bibliográfica e documental, debater os conceitos de Branding e de Experiência do usuário, identificando suas presenças no cenário digital. O objetivo maior era captar atributos capazes de potencializar a identidade de uma marca no meio digital. Para isso, foi escolhida a marca Lola Cosmetics - por acreditar-se que essa apresenta uma forte presença no meio off-line - especialmente se for atualmente comparada com sua presença no meio online. Essa empresa, que produz produtos para cabelos, teve origem no Brasil no ano de 2011 - quando lançou no mercado uma linha de produtos formada por dois itens. Hoje ostenta uma diversidade de produtos para cabelos conjuntamente com uma linha voltada exclusivamente para banho e corpo. Seus produtos, que antes eram adquiridos apenas por e-commerce, hoje podem ser encontrados em pontos de vendas físicos ou em suas Lojas Conceito ${ }^{[3]}$, criadas com o intuito de aproximar os fãs da marca.

A marca Lola Cosmetics também foi definida como objeto de estudo porque apresenta um propósito genuíno e um compromisso com seus consumidores - especialmente quando defende ser vegana, não utilizar testes com animais nem o uso de substâncias cancerígenas em seus produtos. Também possui características marcantes em seu Branding
[3] As lojas conceito são uma tendência do marcado contemporâneo que busca proporcionar um ambiente de aproximação entre marca e cliente. Disponível em: $<$ https://goo.gl/jX4Ls1>. Acesso em: 28 de Abril de 2019. 
identificadas por meio do Estudo de Caso presente na pesquisa que originou este artigo (S/I, 2018). Ao realizar tal análise visualizou-se a necessidade de tornar a qualidade da sua experiência digital compatível com seus pontos físicos. A intenção maior era debater a relevância de uma gestão que buscasse contemplar todos os pontos de contato da marca com seu público - sendo capaz de proporcionar e atribuir valores, muitas vezes intangíveis, à marca. Sendo assim, definiu-se como o objetivo geral da referida pesquisa propor uma experiência interativa para o website da Lola Cosmetics. Para atingir tal intenção, os objetivos específicos estipulados foram: a) apresentar, através de uma revisão bibliográfica e documental, os conceitos de Marketing contemporâneo e experiência de consumo contextualizando suas importâncias para o cenário digital; b) debater os conceitos de Branding necessários para a compreensão do caso que foi analisado; c) expor conceitos acerca da experiência digital analisando recursos interativos; d) investigar e apresentar o caso de mercado Lola Cosmetics; e) realizar um redesign do website da marca que demonstrasse, através de um fluxo, interatividade com base na metodologia de Garret (2011).

Levando em consideração tais percepções que instigaram o estudo, foram inicialmente discutidas as perspectivas do cenário do Marketing e da tecnologia investigadas por meio de Kotler et al (2010), Strunck (2011) e Wheeler (2008). Com esse mapeamento percebeu-se que a globalização e o desenvolvimento tecnológico aproximaram as pessoas, impactando também a sua forma de consumo. Isso vem gerando um padrão no qual os consumidores querem se conectar com as marcas que consomem, buscando não apenas satisfação funcional e emocional nos produtos que escolhem, mas também o sentimento de representação - situação na qual as marcas são capazes de abraçar causas compatíveis com suas visões e valores.

A investigação debateu também as áreas da experiência de usuário e design de interação a fim de compreender 
o comportamento do usuário, sua relação com as interfaces buscando entender, ainda, como o cenário digital pode atender aos anseios desse novo tipo de consumidor. Para isso, estudou-se as perspectivas do design de interação, do motion design e das microinterações como meios de possibilitar a qualidade da experiência do usuário. O objetivo foi o de analisar e propor possibilidades de uma experiência digital centrada na experiência das pessoas, utilizando a Lola Cosmetics como objeto de pesquisa. Com este artigo, contudo, pretende-se apresentar brevemente alguns conceitos que nortearam a referida pesquisa e apresentar parte do resultado da prática projetual atingida por meio da investigação - a partir da exposição da construção de um fluxo do website da marca.

\section{BRANDING: A GESTÃO DA MARCA LOLA COSMETICS}

A presente propagação do mercado e as mudanças nos aspectos de consumo que são capazes de propiciar novas experiências, como compras a distância por exemplo, fazem com que esse mercado se torne ainda mais competitivo. Assim, verifica-se que hoje existe um perfil de consumidor que reconhece e preza pelos valores atribuídos pelas marcas, por isso estas precisam analisar quais são seus propósitos de negócios a fim de buscar fidelizar e aproximar sua relação com seu público potencial - surgindo então a necessidade de pensar estratégias para desenvolver o Branding da marca.

Segundo Martins (2006), o Branding é conceituado como um conjunto de ações administrativas atribuídas ao gerenciamento de uma marca que, quando bem aplicado, é capaz de levá-la a fidelizar pessoas, tornando-se, por vezes, um estilo de vida. Desse modo, é preciso atentar para o desenvolvimento de importantes atributos que se incorporam à estratégia de Branding, tais como: posicionamento; nome; identidade e imagem digital. Tais atributos mencionados são características fortes e presentes na marca carioca de produtos Lola Cosmetics que, segundo ela ${ }^{[4]}$, nasceu com o propósito de fazer a diferença no mundo e na vida de seus consumidores.

[4] Disponível em: <http:// lolacosmetics.com.br/ na-midia/>. Acesso em: 21 de Setembro de 2018. 
Ao se tratar de posicionamento, esse é o fator essencial para orientar as ações de comunicação e as atitudes de uma empresa, ou seja, a marca precisará transmitir para seu público a sua conduta indicando sua maneira de ver o mundo.

Isso é o que ocorre com a marca foco desta investigação, uma vez que a empresa defende uma imagem de empatia e de preocupação com causas ditas nobres, como a preservação do meio ambiente e o cuidado com os animais. Sendo assim, ela deve ter o compromisso de integrar essas mensagens em todos os pilares da sua gestão - de maneira com que torne consistente o seu posicionamento. Para identificar qual é o posicionamento de uma marca é necessário, primeiramente, verificar qual é o público alvo que ela deseja atingir e usar, como diferencial competitivo, fatores perceptíveis pelos consumidores a fim de unificar seus ideais e valores em todos os seus pontos de contato (MARTINS, 2006).

Tais princípios podem ser observados, por exemplo, na Lola Cosmetics através da percepção da marca quanto ao seu apoio, valorização e comercialização de produtos para cabelos crespos e cacheados - isso porque ela iniciou um movimento pela valorização do uso dos cabelos ao natural. Para isso a marca dedicou-se a desenvolver uma linha especialmente para atender as necessidades desse público. Além disso, em seu posicionamento, a empresa argumenta que independentemente de credos e ideologias tem compromisso com o que é certo e não trabalha apenas com cosméticos, mas também com o respeito às consumidoras - apresentando resultados ao alcance de mulheres comuns. Para isso busca inovar através da tecnologia, da comunicação e da sustentabilidade engajada com o meio ambiente e com os animais. Segundo a empresa ${ }^{[5]}$, embora seu sucesso tenha se dado com o público jovem, hoje a Lola consegue conquistar todos os gêneros de diferentes idades em função de sua autenticidade. Desse

[5] Disponível em: <http:// lolacosmetics.com.br/ na-midia/>. Acesso em: 21 de Setembro de 2018. modo, este posicionamento assumido pela marca envolve, dentre outros elementos: o seu nome; as suas embalagens; o 
seu ponto de venda e todos os demais elementos vinculados à organização, que serão apresentados a seguir.

Para tornar-se diferenciado, se sobressair e destacar-se entre os demais do mercado, todo produto necessita de um nome. Por essa razão, são importantes os nomes que são capazes de personificar e deter atributos de valor para uma marca. Wheeler (2008) informa que para a eficácia de um nome, esse deve conter características que o torne significativo, diferenciado e orientado para o futuro, buscando comunicar a essência da marca. Quando se observa o mercado de cosméticos percebe-se uma tendência do uso do nome na diferenciação entre as linhas de produtos. Verificou-se que isso ocorre com a Lola Cosmetics, que apresenta em suas linhas nomes bem-humorados (ver Fig. 1) como o "Eu sei o que você fez na química passada" e "O poderoso cremão" ambos fazendo trocadilhos com os clássicos do cinema "Eu Sei O Que Vocês Fizeram No Verão Passado" (1997) e "O Poderoso Chefão" (1972), reafirmando, dessa forma, seu posicionamento.
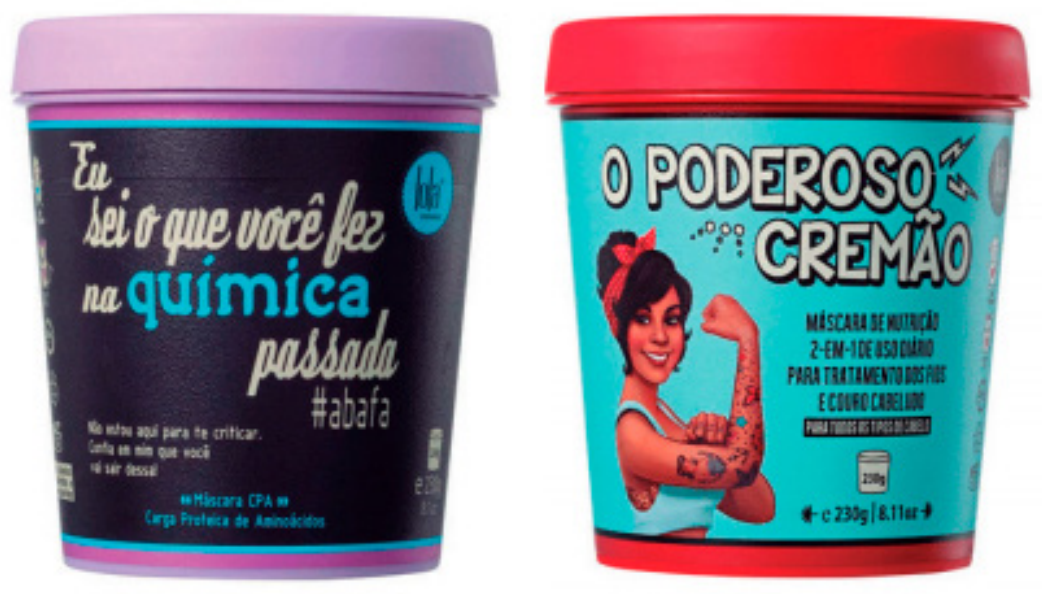

Figura 1 - Produtos da marca. Fonte: Icabelos.com.br. Acesso em 11 de Outubro de 2018. 
Tratando-se ainda de posicionamento da marca, um dos princípios que está vigorosamente atrelado a ele é a sua identidade corporativa, pois é também mediante os sinais gráficos expressados através da identidade de uma marca que se dá a capacidade de traduzir e de expressar tal posicionamento. Isto ocorre, devido ao poder que essa identidade tem na relação de transformar em palpável aquilo que é idealizado (WHEELER, 2008). Portanto, uma marca com elementos de identidade alinhados com seu propósito é capaz de unificar a aparência e o sentido, sendo possível vinculá-la apenas pela linguagem visual expressa em seus produtos. Esta linguagem, conforme Wheeler (2008), está presente nas cores, nas imagens, nas tipografias e nas composições.

Como pode ser demonstrado através dos nomes, cores vibrantes e toque vintage dos produtos da marca (ver Fig. 1), a Lola também busca trazer na sua identidade visual um dos seus preceitos, que é enaltecer a beleza de uma mulher não idealizada. Ainda que ela mencione isso, percebe-se que ao buscar um não padrão, acaba por existir uma idealização de uma mulher forte ao utilizar um tipo de estilo de mulher nas embalagens dos produtos, qual seja: as pin-ups. Contudo, para manter essa não idealização de mulher usou traços femininos bem distintos, que segundo sua criadora ${ }^{[6]}$, foram inspirados em suas amigas, familiares e funcionárias da empresa.

Desse modo, tendo como último fator evidenciado em seu Branding, mas de crescente importância, analisou-se o presente crescimento das tecnologias e redes sociais - que hoje se tornaram praticamente indispensáveis para uma marca pensar na sua presença digital. Para Martins (2006), com o surgimento e a popularização da internet as marcas viram a oportunidade de criar um website como um modelo de portfólio institucional, apresentando suas histórias e seus serviços. Com o passar dos anos, e através do avanço da tecnologia, surgiram as redes sociais; os e-commerce e a mobilidade de acesso através dos smartphones que consequentemente influenciaram as rela-
[6] Disponível em: <http:// tiny.cc/3rmv5y $>$. Acesso em: 28 de Abril de 2019. 
ções interpessoais que a conectividade proporciona - impactando diretamente na forma de experiência do consumidor.

Com o Estudo de Caso realizado observou-se que a expansão da Lola Cosmetics se deu, primeiramente, através do seu e-commerce, e em seguida com a ajuda das redes sociais. Atualmente possui mais de 900 mil seguidores no Facebook que são apelidados pela marca de "Loletes". A responsável pela marca acredita que ter uma boa comunicação com seu público é fundamental, por isso sempre busca através de publicações em suas redes causar engajamento e interação com seus seguidores procurando enaltecer a boa comunicação. Para isso, segundo ela, conta com uma equipe para responder aos comentários do público em suas redes sociais, sempre apresentando um bom humor e espontaneidade - personificando a Lola e tornando-a uma amiga próxima do consumidor.

Ainda com relação ao cenário digital da marca, percebeu-se que a empresa apresenta engajamento, principalmente através de sorteios de produtos. Foca-se em responder mensagens e interagir com seu público e, atualmente, contratou uma agência para o desenvolvimento do seu website - que já existia. Contudo, não possuía conteúdo atualizado e se apresentava apenas na versão para desktop. Este, por sua vez, apresenta determinadas questões que pedem uma usabilidade mais assertiva ao website. Algumas delas, por exemplo, podem ser visualizadas em seu menu de navegação (ver Fig. 2), que possui muitas categorias apesar de se tratarem de um mesmo segmento. A exemplo disso analisou-se que as categorias "Lançamentos", "Por linhas", "Por Produtos" e "Por dramas" poderiam ser formas de filtrar os produtos. Isso também ocorreu no "Lolapédia" e "Lola na mídia", que são categorias que tratam de informações da marca. Nestes casos todos esses itens poderiam se encaixar em uma mesma categoria que se denominariam respectivamente de "Produtos" e "A Lola". 


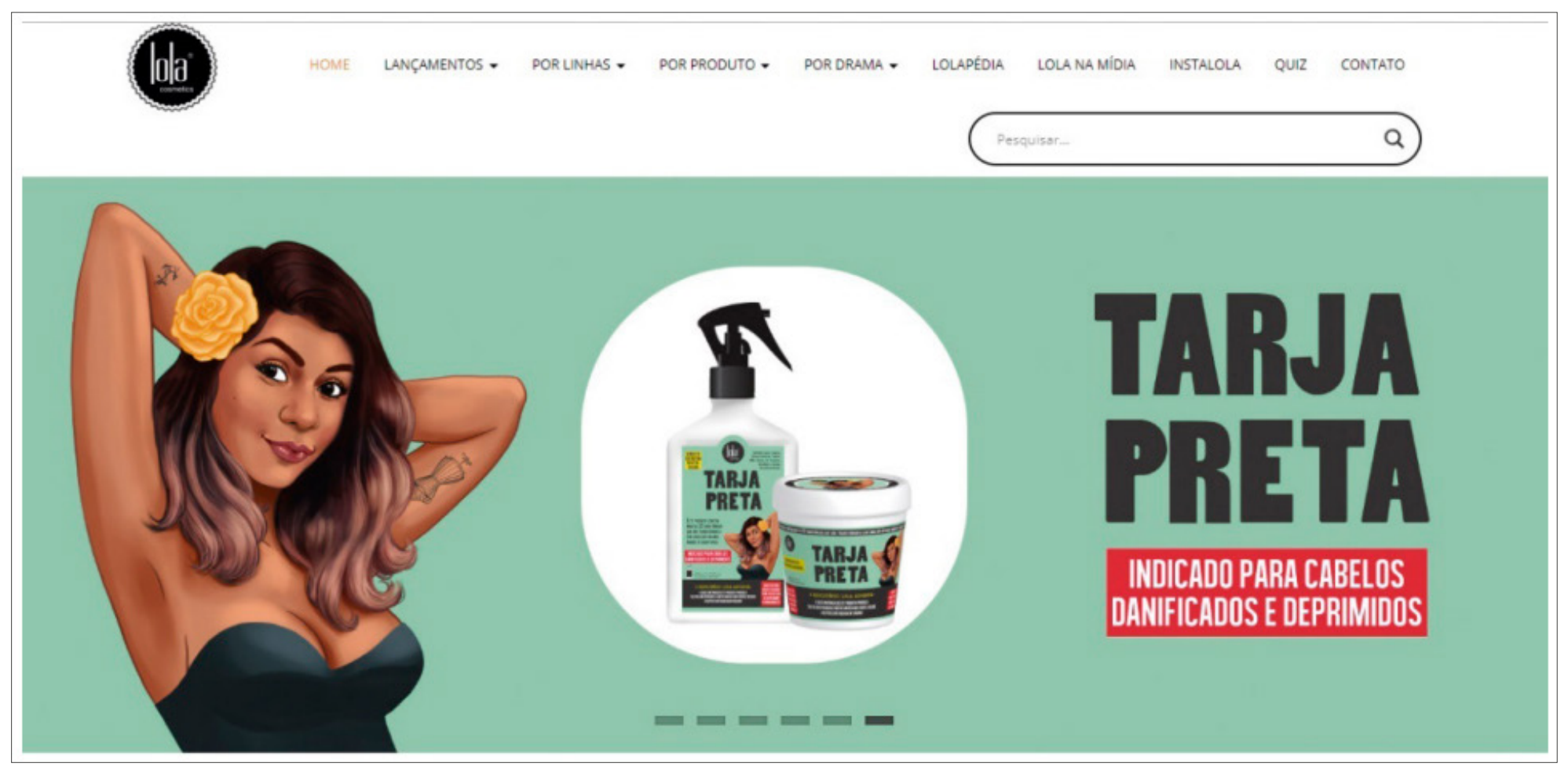

Figura 2 - Versão do website antes do redesign. Fonte: Dados da pesquisa (coletado em 14 de maio de 2018).

Primeiramente a investigação tinha o intuito de buscar soluções para as questões de usabilidade que o site apresentava, entretanto, a marca começou a fazer um redesign, resolvendo tais problemas em sua usabilidade que seriam expostos e solucionados na investigação maior que originou este artigo. Porém, considerou-se que ele ainda poderia e deveria ser aperfeiçoado para se equiparar ao posicionamento que a marca tem nos demais pontos de contato. Essa afirmativa se dá, uma vez que se trata de uma marca que apresenta ideais contemporâneos e os expõe eficientemente apenas em sua Loja Conceito e nos seus produtos autênticos - qualificando, portanto, seus canais offline e deixando de lado os online.

Em relação aos seus ambientes físicos, buscando aumentar a experiência dos clientes com a marca, em Junho de 2017, inaugurou sua primeira Loja Conceito no Barra Shopping, na zona oeste do Rio de Janeiro e hoje possui mais três lojas nesse formato - duas em São Paulo e uma em Brasília.

Ao perceber suas intenções com a inauguração das Lojas Conceitos, bem como sua estética, ficou visível a presença diferenciada da Lola ao comparar seus pontos de contato físicos com o digital. No físico percebeu-se a atenção em proporcionar 
um ambiente que representasse a essência da marca - como salientou a sócia-fundadora da marca para uma matéria sobre a inauguração da Loja Conceito para a revista Veja Rio[7]. A fundadora mencionou que a intenção de abrir uma Loja Conceito foi uma maneira de aproximar os fãs à marca através de um ambiente a ser vislumbrado como a casa da Lola.

Após a compreensão dos atributos presentes no Branding da marca, pode-se concluir, portanto, que ela busca por estratégias compatíveis aos padrões de consumo contemporâneos. Contudo, em relação ao cenário tecnológico, poderia também utilizar-se de mecanismos que fizessem o consumidor ter também uma experiência digital. Para isso, teria que atribuir ao seu website o objetivo de também ser a "casa" da marca - o que justificou as intenções da investigação maior aqui brevemente apresentada.

Desse modo, a seguir será exposto os principais recursos, bem como a metodologia, que guiaram a prática projetual resultante do estudo.

\section{EXPERIÊNCIA E RECURSOS INTERATIVOS}

Quando se trata de experiência digital as pessoas tornam-se usuários que estão em constante interações com máquinas. Contudo, apesar desse cenário ser categorizado como intangível deve-se levar em consideração que a forma de as pessoas se relacionarem nesse ambiente também engloba aspectos cognitivos - que categorizam as experiências como algo subjetivo, isto é, a experiência variará em função do comportamento de cada usuário. Preece et. al. (2013), analisam o comportamento do usuário frente às interfaces abordando a forma como as pessoas se sentem e reagem ao interagirem com as tecnologias denominando-a de interação emocional.

Relacionando tais comportamentos com o cenário contemporâneo que fora evidenciado anteriormente, percebeu-se que marcas engajadas têm como objetivo expor seus valores e proporcionarem experiências por meio da interação com seus consumidores - que se conectam com elas em
[7] Disponível em: <http:// lolacosmetics.com.br/ na-midia/>. Acesso em: 21 de Setembro de 2018. 
todos os seus pontos de contato. Isso inclui a sua presença digital e, em alguns casos, se dá especialmente nesse meio. Como muitas buscam diferencias competitivos para se destacarem em relação aos concorrentes, no cenário digital isso não seria diferente. Para isso, desenvolvem interfaces apropriadas e que possam ser potencializadoras de experiências na web. Quando isso de fato ocorre, torna-se importante atentar para fatores que contemplam a construção de uma interface agradável em todos os planos que englobam aspectos relacionados ao design de interação.

Entende-se por design de interação todo o produto interativo moldado para servir de intermédio para a comunicação e interação humana. Por essa razão, de acordo com Preece et. al. (2013), o termo design de interação enfatiza diferentes aspectos que são levados em consideração ao projetar uma interface, seja ela voltada tanto para um produto físico, quanto digital. Quando se aplica o conceito de design de interação em um contexto digital, também verifica-se que seu processo está atribuído em todas as relações do design com o usuário, ou seja, deve ser levado em consideração a experiência e os aspectos cognitivos do usuário durante seu uso.

Para Garret (2011), que reconhece os websites e interfaces digitais como produtos, as empresas precisam entender a importância de proporcionarem uma experiência de usuário agradável na web e vislumbrarem isso como uma vantagem competitiva, pois também é através desse canal que o usuário será impactado pela marca. Além disso, é necessário ter em mente que, muitas vezes, uma experiência frustrante poderá ser capaz de determinar um não retorno do usuário. Portanto, o processo de design de experiência do usuário tem como objetivo assegurar que todos os aspectos dessa experiência aconteçam de forma consciente e intuitiva. Conforme Garret (2011), essa experiência resultará num conjunto de decisões sobre o site em relação à sua aparência, comportamento e interação que estão vinculadas e irão informar e influenciar todos os aspectos da experiência. Para exemplificar como estas 
decisões estão subordinadas, o autor criou um plano de experiência de usuário no qual propõe cinco planos (ou etapas), que colaboram para o desenvolvimento de interfaces digitais. O presente plano, que fora utilizado como metodologia projetual da investigação, foi composto por etapas de estratégia, escopo, estrutura, esqueleto e superfície.

O plano é adaptado em etapas que se unificam formando um grande pilar, isto é, todas as suas fases dependerão das decisões das demais para funcionar. Contudo, às vezes as decisões poderão ser alteradas e isso fará com que o projeto precise entrar em um ciclo constante de avaliação. As etapas começam com conceitos abstratos até evoluir para definições mais complexas. Para isso, a primeira, e mais abstrata e profunda, é a do plano de Estratégia. É nela em que se define o que se quer comunicar e para quem, momento no qual é realizada muita pesquisa e levantamentos para as definições dos objetivos a serem traçados.

Em um segundo momento define-se o plano de Escopo no qual são estabelecidas as características desse entregável, ou seja, se define quais serão os conteúdos do site, decidindo o que será necessário ou não para, dessa forma, partir para o plano de Estrutura. Este, como enfatiza seu próprio nome, consiste em hierarquizar a informação do site. Nesta fase a etapa já estará a caminho de um plano mais complexo e de grande importância que envolve o trabalho de Arquitetura de Informação (Al), que consistirá em identificar como a hierarquia do conteúdo deverá ser apresentada.

Por fim, chega-se nas etapas mais complexas e mais visuais que se encontram nos planos de Esqueleto e de Superfície - que irão contemplar o desenvolvimento da estrutura do site. No Esqueleto define-se o design de navegação e como será apresentada visualmente as informações do site. Com estas já definidas, é necessário delinear como será a "estrutura óssea" do site, através da elaboração esboços dessa estrutura representada graficamente. Esses, por sua vez, denominam-se de wireframes e servem de apoio para a última etapa: o 
plano de Superfície. Neste último plano será concentrado o desenvolvimento da parte estética do site, que é apresentado por meio de um design visual, sendo assim - com a união de todas as outras etapas formadas - é capaz de proporcionar, além de um site eficiente, um produto digital atrativo.

Após a compreensão de como construir uma interface centrada no usuário é preciso ponderar, durante a sua execução, como alinhar aspectos estéticos que sejam capazes de envolver a experiência do usuário. Para Nojimoto (2009, p. 32) "o design para experiência possui vínculos estreitos com outras abordagens do design no que se refere às relações entre indivíduos e objetos interativos". Portanto, o designer deve aliar-se de referências em abordagens que possam representar um diferencial para construção de interfaces e que provoquem interação.

Atualmente, com o crescente desenvolvimento da tecnologia, e a presença dos aplicativos móveis é possível observar a utilização de recursos no campo da tecnologia e do Motion Design, que são capazes de possibilitar recursos animados que se tornam aliados no desenvolvimento de uma interface interativa. Para Kemilä (2016), que questiona o papel das animações em interfaces, estas tratam-se de um recurso que deve ser cuidadosamente pensado, pois apesar de proporcionar interatividade, se planejadas apenas com fins estéticos podem confundir o usuário.

Por isso, o processo de animação deve estar alinhado e colaborar com a usabilidade. A autora também reforça que as animações têm como principal objetivo informar ao usuário a jornada de seu comando, ou seja, demonstrar de forma mais natural possível qual caminho o usuário está percorrendo. Estas, por sua vez, podem ser representadas em animações simples, como por exemplo, através de microinterações. As microinterações estão tornando-se cada vez mais parte do cotidiano das pessoas, uma vez que as configurações mudam a todo o momento. Saffer (2013), que estuda as microinterações, exemplifica e aponta que apesar de simples, estão atri- 
buídas em várias ações no design de interação. Isso ocorre, por exemplo, ao fazer um login, e sincronizar um dispositivo ou até "curtir" algo nas redes sociais e por mais pequenas que pareçam, quando bem planejas são capazes de transformar uma ação comum em uma experiência memorável.

Além das microinterações, outros aspectos estéticos na fusão da tecnologia com os princípios do Motion Design possibilitam proporcionar interfaces dinâmicas. Isso se dá, por exemplo, através da fusão de interações com rolagem parallax que se trata de uma técnica da computação gráfica utilizada na web na qual o fundo do site se movimenta de forma mais lenta que seu plano, causando um efeito de profundidade na interface.

A partir do exposto, foi possível verificar que os recursos que possibilitam uma experiência de interatividade podem identificar o quanto as marcas ganhariam ao se diferenciarem quando buscam desenvolver tais aspectos para potencializarem a presença digital em seus websites. É a partir desse entendimento que, a seguir, apresenta-se como esses conceitos foram utilizados no redesign do website da Lola.

\section{PRÁTICA PROJETUAL: REDESIGN INTERATIVO PARA A MARCA LOLA COSMETICS}

Para o desenvolvimento prático projetual foi proposto um redesign interativo do website para a Lola Cosmetics que se deu por meio de um fluxo - que guiasse o usuário da home até a página de um produto da linha "Drama Queen" - demonstrando essa interatividade. Para isso, como já mencionado, utilizou-se a metodologia conforme os planos de Garret (2011). Esta, como exposto, contribuiu para a orientação da experiência, pois parte de uma forma abstrata para uma mais tangível.

É importante destacar que no percorrer das aplicações das técnicas presentes na metodologia, principalmente em seus planos iniciais, estes denominados de Estratégia e Escopo, foram consideradas as características presentes na marca objeto da investigação. Estas, por exemplo, se referem ao seu 
público alvo - importante informação para a definição de personas, assim como também os recursos potencializadores de experiência - identificados no referencial teórico da pesquisa. Esses foram usados para a definição do caminho de estratégia desenvolvido. Portanto, as etapas que são evidenciadas a seguir possuem adaptações no que se refere às práticas que percorrem estes planos, isso ocorreu uma vez que o Estudo de Caso e o referencial desenvolvido serviram de parâmetro, conjuntamente com o atual site da marca, para indicar o percurso e as referências para as técnicas realizadas.

Dessa forma, com base nos elementos de interação apresentados, como objetivo do plano de estratégia buscou-se proporcionar uma experiência interativa através de elementos como microinterações e interações animadas em transições de página. Estabeleceu-se, ainda, que tais elementos interativos fossem capazes de fazer os usuários encontrarem mais do que apenas informações sobre a marca, tornando-se também um canal de acesso que viesse a qualificar o que a Lola propõe em seu posicionamento e marca: modernidade e inovação.

Após os objetivos definidos, seguiu-se para o passo de escopo, momento no qual foi feita uma avaliação dos elementos de Especificações Funcionais e Requisitos de conteúdo. Esse teve como o intuito fazer um levantamento para analisar quais são as funcionalidades e informações presentes no site e quais requisitos deveriam fazer parte do mesmo. Com isso, seria possível identificar quais recursos seriam necessários para realizar as funcionalidades do website, assim como o que seria importante e essencial para cada especificação funcional.

Como passo de estrutura, foram realizadas abordagens que envolveram fatores que colaboraram para a compreensão da maneira pela qual os usuários se comportam e pensam. Isso ajudou no entendimento de como se deu a estrutura do website, garantindo uma experiência bem sucedida ao ser usado. Desse modo, as técnicas aplicadas foram as de: Card Sorting, com o objetivo de analisar a forma como os usuários identificavam a categorização do website; Sitemap, usan- 
do como base e análise dos resultados coletados da aplicação do Card Sorting. Com isso, determinou-se os possíveis caminhos que o usuário percorreria através do design de interação e como se daria a arquitetura de informação do website que se recorreu no plano de esqueleto; e Fluxograma onde se evidenciou qual o caminho que o usuário iria percorrer ao executar a tarefa determinando, também, qual fluxo fora escolhido para demonstrar a interação da prática projetual.

Os resultados para as etapas mais concretas, concedidas através dos planos de Esqueleto e Superfície, foram iniciados por meio de uma pesquisa visual. Esta, para Lupton (2013), tem como objetivo analisar conteúdo a fim de gerar ideias e pontos de vistas sendo capaz de criar soluções visuais. Sendo assim, a pesquisa foi guiada através de três passos. O primeiro foi o de coleta - que consistiu em identificar tantos atributos a serem usados nas funcionalidades do website quanto explorar os aspectos da Lola Cosmetics - expostos principalmente na apresentação de sua loja conceito. A próxima etapa consistiu em visualizar tendências sobre a marca. Dessa forma, optou-se por realizar dois painéis: um destacando padrões da marca com a intenção de firmar uma identidade para o redesign e outro selecionando elementos interativos que serviriam de alicerce para o desenvolvimento do site (ver figuras 3 e 4).

Como último passo foram analisados os conteúdos dos painéis, momento no qual foram registradas as percepções acerca dessa pesquisa visual. Com isso chegou-se às seguintes estratégias visuais: estabeleceu-se que o website deveria conter elementos presentes em suas Lojas Conceitos (tal como a faixada com a marca em neon da loja); além de texturas rústicas amadeiradas presentes em grande parte do ambiente; uso de cores vibrantes; tipografias marcantes e também a utilização das elipses - uma vez que essa se faz presente no símbolo da marca. Além disso, também pela sua capacidade de sugerir expansão, profundidade e interatividade, fatores que foram explorados no redesign. 

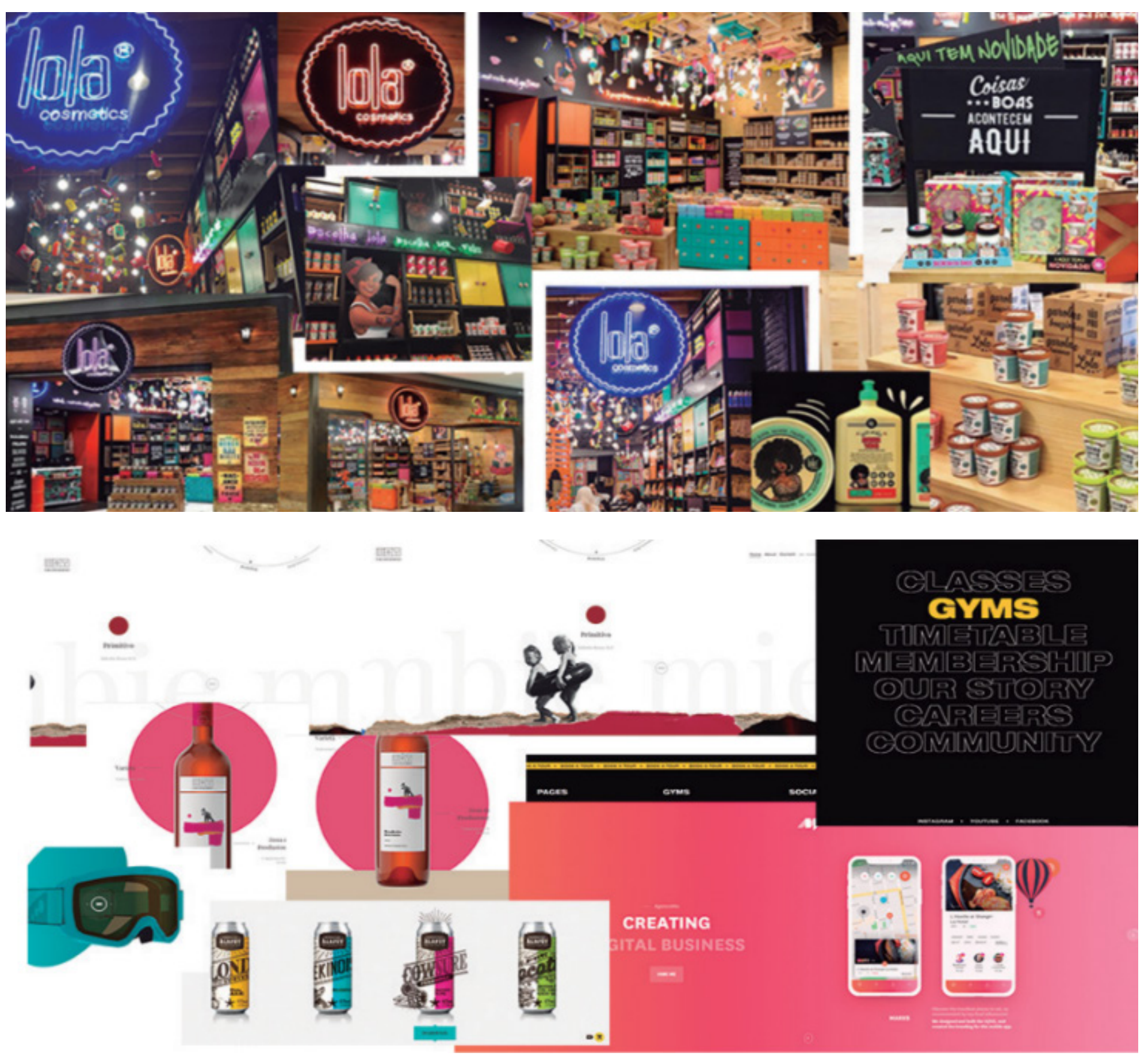

Figuras 3 e 4 - Painéis da Pesquisa Visual. Fonte: Dados da pesquisa.

Como a coleta dos elementos interativos dependia de necessidades dinâmicas, a pesquisa que originou este artigo (S/I, 2018), criou uma lista que contém todos os endereços dos sites que foram usados para a coleta da pesquisa visual, assim como os selecionados para o desenvolvimento do painel. Cada link apresenta, respectivamente, uma descrição 
que contém o que fora usado do site como referência e/ou inspiração e como esses foram aplicados na prática.

Tendo como referencial a coleta de elementos, foram desenvolvidos wirefames (ver Figura 5), que definiram o alicerce da superfície do website e também Storyboards (ver Figura 6), apresentada a seguir, que contribuíram para originar as interações que foram aplicadas no redesign.
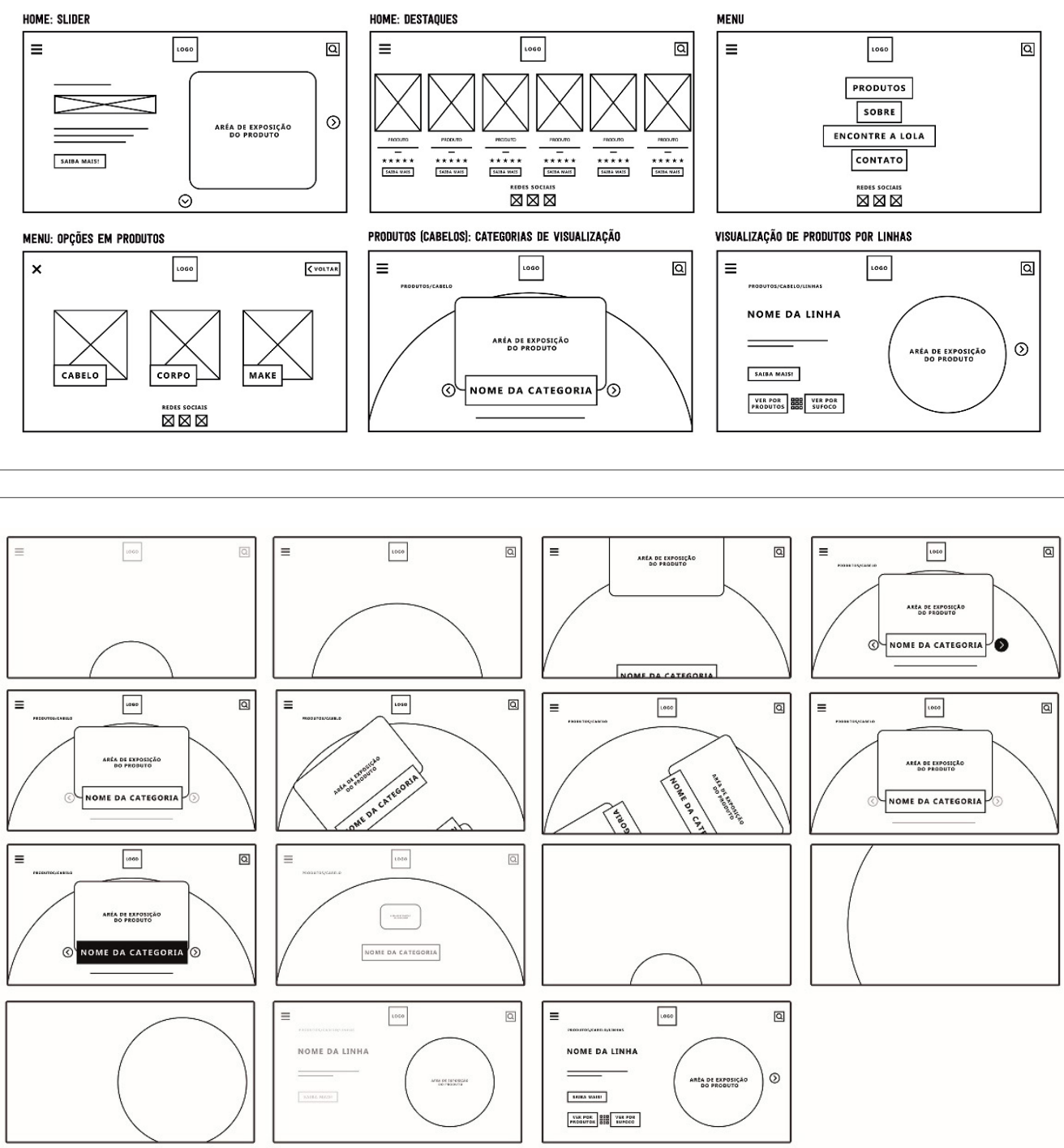

Figura 5 - Principais

Wireframes desenvolvidos. Fonte: Dados da pesquisa.

Figura 6 - Storyboard. Fonte: Dados da pesquisa. 
Ao analisar cada passo no decorrer do Storyboard foi utilizada a circunferência para evidenciar a transição entre as páginas, assim como o modo de introdução de elementos contidos nelas. Portanto, pode-se concluir que foi fundamental para esse processo de criação pensar a construção das interações conjuntamente com o desenvolvimento dos wireframes.

Por fim, com base nos métodos realizados no plano de esqueleto definiu-se a última etapa: a superfície. Nesta levou-se em consideração a coleta de elementos realizada e as decisões definidas no plano de esqueleto. A partir delas foi desenvolvida a direção de arte dos wireframes apresentados a seguir (ver Figura 7).

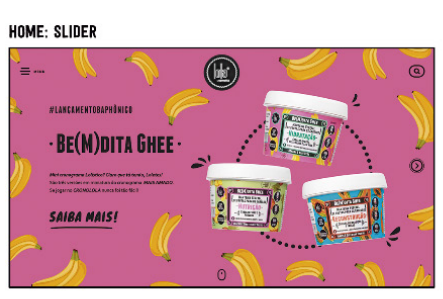

MENU: OPÇ̄̃ES EM PRODUTOS

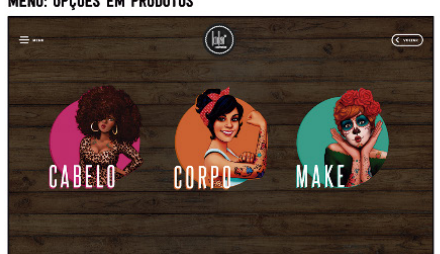

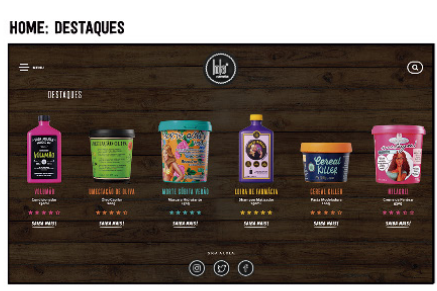

PRODUTOS (CABELOSS: CATEGORIAS DE VISUALIZAĢ̃̃o

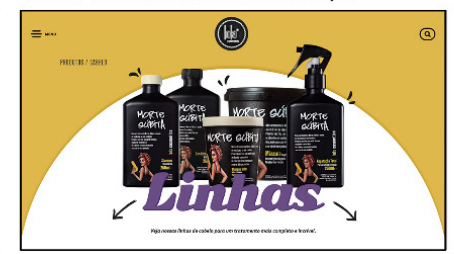

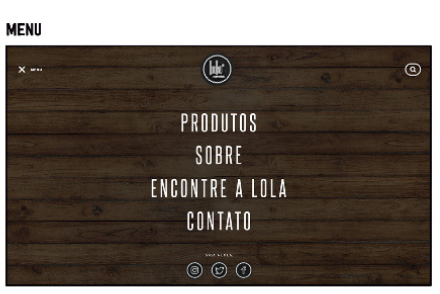

VISUALZZAÇ̃̃o DE PRODUTOS POR LINHAS

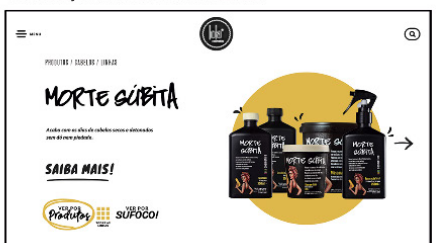

Figura 7 - Direção de arte dos wireframes. Fonte: Dados da pesquisa.

Nessa etapa definiram-se as cores, as texturas e também as tipografias usadas. Também se optou por padrões a serem seguidos no desenvolvimento da interface do site, que buscaram como referências os materiais já produzidos pela marca bem como o ambiente de sua Loja Conceito a fim de proporcionar uma unidade de todos os seus canais.

Torna-se importante destacar que um dos maiores desafios no desenvolvimento da interface foi estabelecer como desenvolver uma direção de arte para o website a partir dos padrões pré-estabelecidos na pesquisa visual. Isso porque a identidade visual da marca já é muito destacada e a loja aca- 
ba por torna-se um ambiente de forte apelo. Contudo, um dos princípios da boa experiência de usuário, principalmente ao interagir com uma interface digital, é a sua simplicidade - que tem por intenção facilitar tanto sua curva de aprendizado quanto seu objetivo. Por esses motivos as telas de linhas e também a de produto, demonstrada a seguir (ver Figura 8), foram pensadas com um background branco, apresentando em algumas delas com sutis texturas de poá - que é um clássico vintage alinhado com a identidade visual da marca. Considerou-se também que ao utilizar o rótulo das embalagens em destaque esse seria capaz de proporcionar uma unidade visual para o website como um todo, isto é, no restante das páginas individuais de cada linha.

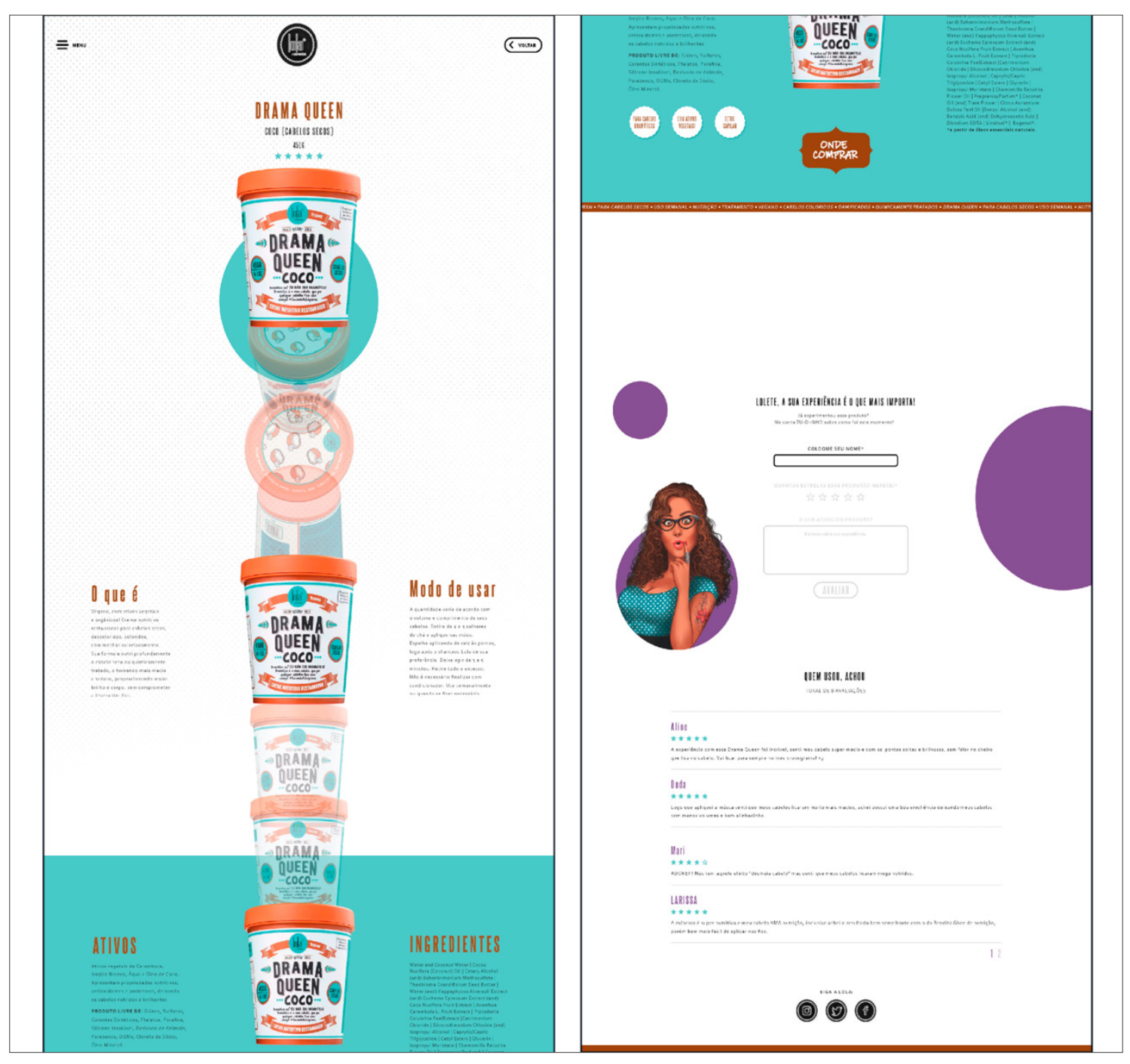

Figura 8 - Página do produto Drama Queen Coco. Fonte: Dados da pesquisa. 
Na página de produto, a principal interação decidida foi a de scroll. A interação é demonstrada conforme o usuário for deslizando a página na qual o produto que estará em evidência no centro da tela irá girar em $360^{\circ}$ no eixo $Y$ até estagnar - revelando as primeiras informações sobre o produto. Novamente através do scroll, o produto irá deslizar em direção à sua posição final, estagnando sob o botão que permite ver os locais de venda do mesmo. Neste momento o usuário também teria a possibilidade de rotacionar o produto em seu eixo $X$, para visualizar aspectos do rótulo da embalagem. Tags e uma faixa em movimento também foram acrescentadas para reforçar as principais características do produto, pretendendo com isso a aproximação do consumidor para com o produto analisado. Além disso, ao usuário ir em direção ao Footer da página, encontrará uma seção de comentários funcionalidade que já era existente no atual website. Nela será possível avaliar e deixar relatos sobre a experiência com o produto.

Além do desenvolvimento das telas que finaliza a jornada do fluxo escolhido, vale ressaltar que foi desenvolvido um breve Guia de Estilos (Design System), que buscou demonstrar os principais elementos selecionados neste redesign, bem como boas práticas a serem aplicadas na interface em futuros projetos. Tanto o Guia de estilos, como os demais Wireframes e as telas desenvolvidas, podem ser evidenciados na pesquisa maior que deu origem a este artigo (S/I, 2018).

Por fim, para demonstrar os resultados obtidos com a prática projetual aqui exposta, foi desenvolvido um vídeo ${ }^{[8]}$ que além de apresentar as soluções de direção de arte para o website, demonstra também todas as interações realizadas no fluxo que teve por propósito evidenciar como se deu o resultado da prática da investigação.

\section{CONSIDERAÇÕES FINAIS}

A investigação aqui debatida teve início pela percepção da necessidade de integração do posicionamento de uma marca em todos seus pontos de contato - em especial, no caso apresen-
[8] O vídeo com a demonstração do resultado da prática projetual da investigação pode ser acessado através do link: <https://vimeo. com/303817401>. 
tado, integrando o meio digital às ações realizadas fora dele. Com isso, foi possível identificar a importância do papel do designer digital frente ao cenário contemporâneo - uma vez que hoje os consumidores estão presentes, dependendo do tipo de produto e serviço comercializado, tanto on-line quanto no off-line. No caso apresentado, observou-se que a marca apesar de ter nascido no mundo on-line, não aprimorou sua presença nesse meio - o que tornou a investigação viável.

Por meio dos esforços empreendidos para a execução da prática resultante da investigação, acredita-se que o objetivo maior da pesquisa e deste artigo foram atingidos. Torna-se importante destacar que o levantamento dos recursos interativos demonstrou as inúmeras possibilidades ainda a serem exploradas neste contexto digital, incluindo a sua capacidade de comunicação através de interações e de como estas podem operar com relação ao do Branding de uma marca.

Portanto, apesar dos desafios enfrentados, acredita-se que o website elaborado propicia uma aproximação e percepção do público da Lola sobre os atributos e o posicionamento da marca. Ainda que se leve em consideração que as experiências abordam sentidos, possuindo um caráter totalmente subjetivo, identificar atributos da gestão de imagem da Lola contribuiu para produzir uma interface, bem como interações, que exploram a identidade da marca.

Diante de todo exposto conclui-se a exposição desses resultados esperando que eles contribuam com futuras pesquisas que visam proporcionar, acima de tudo, experiências às pessoas entendendo que em um mundo que se torna cada dia mais digital todo o projeto centrado na experiência do usuário fará diferença. 


\section{REFERÊNCIAS BIBLIOGRÁFICAS}

GARRET, James Jesse. The Elements of User

Experience: User-Centered Design for the Web and Beyond. California: New Riders, 2011.

KEMILÄ, Jenna. Communication with motion in user

interface Supervisor. Oulu: OUAS, 2016. Degree programme of Media and Communication, Visual communication, Oulu University of Applied Sciences, 2016.

KOTLER, Philip. et al. MARKETING 3.0: as forças que estão definindo o novo marketing centrado no ser humano. Rio de Janeiro: Elsevier, 2010.

LOLA COSMETICS. História. Disponível em: <http://lolacosmetics.com.br/historia/>. Acesso em: 7 de Set. de 2018.

LUPTON. Ellen Graphic Design Thinking: intuição, ação e criação. São Paulo: Editora G. Gili, 2013.

MARTINS, José Roberto. Branding, um manual pra você criar, gerenciar e avaliar marcas. Global Brands, 2006.

NOJIMOTO, Cynthia. Design para experiência: processos e sistemas digitais. São Paulo: USP, 2009. Dissertação, Teoria e História da Arquitetura e do Urbanismo, Escola de Engenharia de São Carlos, Universidade de São Paulo, 2009.

PREECE, Jenny. et. al. Design de Interação:

Além da Interação Humano-Computador. Editora Bookman, São Paulo: 2013.

SAFFER, Dan. Microinteractions. United States of America: O'Reilly books, 2014.

STRUNCK, Gilberto. Compras por impulso! Trade merchandising e o poder da comunicação e do design no varejo. Rio de Janeiro: 2AB, 2011.

WHEELER, Alina. Design de identidade de marca. Porto Alegre: Ed. Bookman, 2008. 